\title{
LA POLÍTICA EXTERIOR MEXICANA: SUS PRINCIPIOS FUNDAMENTALES
}

\begin{abstract}
Alonso GóMEZ-RoBLEDO VERDUZCO
RESUMEN: El autor analiza los principios rectores que rigen la política exterior mexicana consagrados en el artículo 89, fracción IX, de la carta magna desde el 11 de mayo de 1988 en que se hizo la publicación en el Diario Oficial de la Federación, cuestionando la necesidad de elevarlos a tal jerarquía aun y cuando ya habían sido plasmados en otros instrumentos jurídicos internacionales, como la Carta de la Organización de las Naciones Unidas. De igual manera, hace un estudio minucioso de cada uno de estos principios y su desarrollo en la

ABSTRACT: The author analyses the leading principles in Mexican foreign policy, enshrined in article 89, paragraph IX of the Constitution since May 11, 1988, when the article was published in the Official Gazette. He challenges the need to raise such principles to that level, notwithstanding the fact that they had already been incorporated in other international instruments, such as the United Nations Charter. Similarly, he makes a detailed study of each of these principles, and their development in international doctrine and case law.
\end{abstract} doctrina y jurisprudencia internacionales. 
SUMARIO: I. Introducción. II. No intervención. III. La autodeterminación de los pueblos. IV. La solución pacífica de controversias. V. La proscripción de la amenaza o el uso de la fuerza en las relaciones internacionales. VI. La igualdad jurídica de los Estados. VII. La cooperación internacional para el desarrollo. VIII. La lucha por la paz y la seguridad internacionales. IX. Conclusión.

\section{INTRODUCCIÓN}

Por decreto aparecido en el Diario Oficial de la Federación el 11 de mayo de 1988, se reformó la fracción IX del artículo 89 de la Constitución Política de los Estados Unidos Mexicanos.

De conformidad con dicho decreto, el titular del Poder Ejecutivo, en la conducción de la política exterior, deberá observar los siguientes principios normativos:

- La no intervención

- La autodeterminación de los pueblos

- La solución pacífica de controversias

- La proscripción de la amenaza o el uso de la fuerza en las relaciones internacionales

- La igualdad jurídica de los Estados

- La cooperación internacional para el desarrollo

- La lucha por la paz y la seguridad internacionales

Lo primero que hay que preguntarnos es si existe una necesidad real de reformar la Constitución Política, para consagrar en forma expresa los principios rectores de nuestra política exterior.

A primera vista no parece que hubiera una necesidad real de reformas, porque estos principios están insertos en multitud de instrumentos internacionales, de los cuales México es parte por haberlos suscrito, aprobado, ratificado o adherido. Para no citar sino dos de los principales instrumentos, bastaría con mencionar por un lado la ratificación de nuestro país, el 7 de noviembre de 1945, de la Carta de la Organización de las Naciones Unidas, y por el otro, la ratificación de México, el 23 de noviembre de 1948, de la Carta de la Organización de los Estados Americanos (reformada ésta por el Protocolo de Buenos Aires de 1967, y por el de Cartagena de Indias de 1985). 
Tanto en la Carta de San Francisco de 1945, como en la Carta de Bogotá de 1948, los principios rectores de nuestra política exterior se encuentran expresamente consagrados en los mismos principios, propósitos y objetivos de ambas convenciones, pero además se encuentran plasmados - en una forma u otra-, a todo lo largo de los capítulos referentes a los derechos y obligaciones de los Estados miembros, en una forma clara, precisa y jurídicamente inobjetable.

De conformidad con el mismo artículo 133 de nuestra Constitución Política, estas dos cartas — la de la ONU y la de la OEA — son tratados internacionales que fueron en su momento aprobados por el Senado de la República, y por lo tanto son "ley Suprema de toda la Unión".

Pero también, no podemos dejar pasar por alto que los llamados principios rectores de la fracción X del artículo 89 de nuestra Constitución forman parte de lo que se llama el "derecho internacional consuetudinario", es decir, el derecho internacional general, que obliga por igual a todas las naciones, independientemente de tratados, pactos, acuerdos o convenciones internacionales.

Ahora bien, si vemos con cuidado el precepto reformado sobre nuestras directrices de política exterior, no podemos saber si su enumeración es solamente de carácter enunciativo, o si, por el contrario, es una enumeración de carácter exhaustivo, lo que en el futuro podría generar problemas delicados de política constitucional y de política internacional, lo que conllevaría seguramente al replanteamiento de "nuevos principios" y, con ello, nuevas y problemáticas reformas constitucionales.

Sin embargo, y posiblemente sea éste su mérito mayor, el elevar a rango constitucional las normas directrices de nuestra política exterior permite con ello una mayor divulgación de los mismos, una mejor comprensión de su significado y alcances, y obliga a un análisis más cuidadoso de éstos, tanto en teoría jurídica, como en la práctica política. ${ }^{1}$

1 En este sentido, véase Rabasa, Emilio O., "Nota introductoria”, Los siete principios básicos de la política exterior de México, México, Comisión Nacional de Asuntos Internacionales, 1993, p. 13: "Abierta la posibilidad de enmarcar constitucionalmente nuestra doctrina internacional, la nueva norma podría no contener todos los principios fundamentales y perennes de México en esta materia. Más aún, quizás sería el medio para que cada presidente asentara sus preferencias de momento en esta materia". 


\section{NO INTERVENCIÓN}

El carácter extremadamente multiforme de la "intervención" en las relaciones internacionales provoca de hecho que el respeto de este principio sea mucho muy aleatorio.

Todo Estado debe abstenerse de aplicar, fomentar o provocar el uso de medidas económicas, políticas o de cualquier otra naturaleza, para obligar a un tercer Estado a subordinar el ejercicio de sus derechos soberanos, y para obtener de éste, ventajas o beneficios de toda índole.

Todos los Estados deben abstenerse de organizar, ayudar, fomentar, financiar, provocar o tolerar actividades armadas, subversivas o terroristas destinadas a cambiar a través de la violencia el régimen de un tercer Estado, al igual que el querer intervenir en las luchas intestinas de cualquier otro Estado. ${ }^{2}$

El juez de la Corte Internacional de Justicia, Alejandro Álvarez, en su opinión individual en el caso del Estrecho de Corfú, sostuvo, a propósito del argumento inglés sobre la operación de barrido de minas, y según el cual constituía ésta una intervención de autodefensa justificada, que en realidad se trataba de una violación de la soberanía albanesa.

La Corte, dijo el juez A. Álvarez, debe reafirmar cada vez que haya lugar, que la intervención, así como todo acto de fuerza, no están permitidos bajo ninguna forma y bajo ningún pretexto en las relaciones internacionales. $^{3}$

El principio de no intervención pone en juego el derecho de todo Estado soberano para conducir sus asuntos sin ningún tipo de injerencia exterior.

Este principio de no intervención, aun y cuando sus infracciones son frecuentes, forma parte integrante al derecho internacional consuetudinario.

La existencia del principio de no intervención en la opinio juris de los Estados está fuertemente apuntalada, dijo la Corte (1986), en una bien

2 Véase Ouchakov, "La compétence interne des États et la non-intervention dans le droit international contemporain”, Rec Cours Ac. H., 1974. El artículo 2o., párrafo 7, de la Carta de la ONU, que prohíbe la intervención en "asuntos que son esencialmente de la jurisdicción interna de los Estados", figuraba ya en el Pacto de la Sociedad de Naciones en su artículo 15, párrafo 8, pero dejaba al Consejo o a la Asamblea de la Sociedad de Naciones, toda la latitud para ejercer funciones de mediador o conciliador. Por su parte, la Carta de la OEA consagra este principio de no intervención en su artículo 18, excluyendo todo tipo de injerencia o de "tendencia atentatoria de la personalidad del Estado". Véase Cançado Trindade, A. A., "The Domestic Jurisdiction of States and the Practice of the UN and Regional Organisations", ICLQ, 1976, pp. 715-765.

3 Véase Affaire du Détroit de Corfou (fond) "Arret du 9 avril 1949", Recueil des Arrets, Avis Consultatifs et Ordonances. Opinion Individuelle de M. Álvarez, p. 45, punto VIII. 
establecida y muy importante práctica internacional. Este principio puede presentarse como un corolario del principio de igualdad soberana de los Estados. ${ }^{4}$

La Corte de La Haya, en su sentencia de 1986, expresó con toda claridad que el principio de no intervención es un principio que prohíbe a un Estado o grupo de Estados intervenir directa o indirectamente en los asuntos internos o externos de otro Estado.

La intervención prohibida debe, por lo tanto, recaer sobre temas o materias a propósito de las cuales el principio de la soberanía de los Estados permite a cada uno de ellos decidir con absoluta libertad.

Concretamente, dice la Corte, esa libertad se ve reflejada en la libre elección del sistema político, económico, social y cultural de cada Estado, y de la formulación de su política exterior.

La intervención será ilícita cuando a propósito de materias tales como las anteriores, que deben permanecer en total libertad, se utilizan medios de apremio o compulsión.

Estos medios de apremio de medidas de coerción son el elemento constitutivo de la intervención que se prohíbe precisamente - formando su esencia misma-, y esto es particularmente evidente en el caso de una intervención, utilizando el uso de la fuerza, ya sea en forma directa, a través de una acción militar, o sea en su forma indirecta, a través del apoyo de actividades armadas subversivas o terroristas en el interior de un tercer Estado.

Estas formas de acción son ilícitas, dice la Corte, tanto a la luz del principio del no uso de la fuerza, como del principio de no intervención. ${ }^{5}$

\section{LA AUTODETERMINACIÓN DE LOS PUEBLOS}

La mayor parte de la doctrina y jurisprudencia internacionales están de acuerdo en considerar que esa parte de la adopción de la Carta de las Naciones Unidas que la noción de la autodeterminación de los pueblos se convierte en un principio clave del derecho internacional contemporáneo.

Entre los propósitos de las Naciones Unidas se cuenta el de: "Fomentar entre las naciones relaciones de amistad basadas en el respeto al prin-

4 Véase "Affaire des Activités Militaries et Parmiliataires au Nicaragua et contre Celui-ci" (Nicaragua c. États-Unis d'Amerique), Fond, Arret du 27 juin 1986, Recueil des Arrets, Avis, Consultatifs et Ordonnances, CIJ, p. 106, numeral 202.

5 Ibidem, pp. 107 y 108, numeral 205. 
cipio de la igualdad de derechos y al de la libre determinación de los pueblos" (artículo 1o., párrafo 2).

En forma semejante, la Carta establece más adelante en su artículo 55 que: "Con el propósito de crear las condiciones de estabilidad y bienestar necesarios para las relaciones pacíficas y amistosas entre las naciones basadas en el respeto al principio de la igualdad de derechos y al de la libre determinación de los pueblos, la Organización promoverá: a) niveles de vida más elevados..., $b$ ) solución de problemas internacionales de carácter económico, social y sanitario..., $c$ ) el respeto universal a los derechos humanos".

La Resolución 1514 (XV) adoptada por la Asamblea General de Naciones Unidas el 14 de diciembre de 1960 es considerada como la verdadera base del proceso de descolonización que se traduciría precisamente a partir de esas fechas en la creación de numerosos Estados, que irían sumándose paulatinamente a la organización internacional.

De conformidad con dicha Resolución 1514 (89 votos a favor, cero en contra y 9 abstenciones), un territorio no autónomo podría alcanzar su plena autonomía de diversas maneras:

a) Convirtiéndose en un Estado independiente y soberano.

b) Asociándose libremente a un Estado independiente.

c) Integrándose a un Estado independiente.

Hay que reconocer que esta "Declaración sobre la concesión de la independencia a los países y pueblos coloniales", propuesta inicialmente por Khrushchev, no era suficiente para otorgar el derecho a los pueblos a la autodeterminación, un principio aceptado y universalmente obligatorio de derecho internacional.

Sin embargo, debemos también reconocer que la evolución jurídica subsecuente permitió situar este derecho a la autodeterminación sobre el mismo plano que otros principios, como lo es el relativo a la prohibición de la agresión o el del arreglo pacífico de las controversias.

En el plano doctrinal siempre se opusieron dos corrientes principales. Un primer grupo de autores sostenían que si el derecho de los pueblos a la autodeterminación se consagraba como un instrumento convencional vigente, como la Carta, entraba ipso facto a formar parte del derecho internacional positivo, y no se le podía seguir considerando como un mero principio de orden político, y que por lo tanto los Estados estaban jurídi- 
camente obligados a su respeto y observancia. Ello podría implícitamente interpretarse además como un derecho existente de los pueblos a la secesión y a la independencia.

La otra corriente principal sostenía que en realidad la Carta de las Naciones Unidas, al consagrar el derecho a la autodeterminación, lo hacía como una finalidad que era deseable alcanzar en el futuro, como un ideal político, pero nunca como una verdadera obligación jurídica. ${ }^{6}$

Sin embargo, como mencionamos anteriormente, la historia y práctica internacionales se encargarían de otorgarle un pleno valor jurídico al principio de la autodeterminación de los pueblos, paralelamente a su incuestionable valor político por referirse a un ideal democrático.

Este proceso de reafirmación del principio jurídico de autodeterminación tendría un desarrollo y alcance mayores con la adopción por la Asamblea General de la "Declaración relativa a los principios del Derecho Internacional sobre las relaciones de amistad y cooperación entre los Estados de acuerdo a la Carta de las Naciones Unidas" del 4 de noviembre de 1970 y votada unánimemente por todos los Estados miembros.

Esta Resolución 2625 (XXV) dispone que la creación de un Estado soberano e independiente, "la libre asociación o la adquisición de cualquier otro status político libremente decidido por un pueblo constituyen medios válidos para ejercer su derecho a la autodeterminación”.

La Corte Internacional de Justicia, en su Opinión Consultiva sobre el Sáhara Occidental, después de reafirmar una vez más la validez jurídica del derecho a la autodeterminación, sostuvo que este principio, entendido como respuesta a la necesidad de respetar la voluntad libremente expresada por los pueblos, no se ha encontrado disminuido por el hecho de que en ciertos casos la Asamblea General no haya creído necesario exigir la consulta previa de los habitantes de tal o cual territorio. Estas excepciones se explican, dijo la Corte, ya sea por la consideración de que una cierta población no constituía un "pueblo" con capacidad de aspirar a la autodeterminación, o por la convicción de que una consulta hubiera sido innecesaria en razón de las circunstancias particulares. ${ }^{7}$

Por otro lado, no cabe duda que en las múltiples declaraciones y resoluciones que ha emitido la ONU no se encuentra un significado preciso y una connotación única que deban dársele al término "pueblo".

6 Vid. S. Calogeropoulos Stratis, Le droit des peuples à disposer d'euxmêmes, pref. de René Cassim, Bruselas, Bruyalant, 1973, p. 388.

7 Recueil des Arrêts, Avis Consultatifs et Ordonnances, 16-10-59, párrafo 59. 
La razón principal de ello parece residir en el hecho de que este "derecho a la autodeterminación" no está en principio vinculado a las características o rasgos particulares de una colectividad, sino a la situación concreta en la cual se encuentra. En este sentido, los "pueblos" que pueden gozar de tal derecho serían en principio aquellos que están subyugados por un dominio o explotación extranjeras.

Aquí surge precisamente otro de los muchos problemas que se encuentran imbricados en este tema. Nos referimos al fenómeno de la secesión. Este problema es de una peculiar gravedad por lo que respecta a los nuevos Estados, en donde frecuentemente nos encontramos con una población muy heterogénea y con un poder político de débil o nula efectividad y presencia internacional.

No es difícil comprender que un pueblo consolidado y bien arraigado, con una misma historia milenaria, fuerte tanto al interior como al exterior, pueda en un caso concreto tolerar la secesión de un grupo étnico que no ha podido asimilarse al resto del grupo social. Pero el resultado será completamente diverso cuando se trate de Estados que se encuentran compuestos de unas veinte o treinta etnias diferentes y posiblemente hostiles entre sí. Si el Estado, en esta hipótesis, admite la secesión de uno de los grupos o etnias, corre el inminente riesgo de verse envuelto en una vorágine secesionista, que pronto lo reducirá a su propia desaparición como sujeto de derecho internacional.

Es indudable que el derecho a la autodeterminación que comúnmente ha llegado a ejercerse por "pueblos" insertos o integrados dentro de un Estado soberano, cuestiona y por lo tanto pone en peligro una real o supuesta unidad nacional e integridad territorial.

De conformidad con varias resoluciones de Naciones Unidas, un pueblo sometido al dominio de una potencia extranjera estaría, como hemos visto, en su derecho a independizarse, pero por otra parte en estas mismas resoluciones se encuentra también la idea de que no existiría esa pretendida "dominación", en caso de que el Estado en cuestión estuviera dotado de un gobierno representativo (si) del conjunto del pueblo perteneciente al mismo. Es aquí precisamente donde puede verse con claridad la serie de ambigüedades, contradicciones y fluctuaciones que pueden envolver a este controvertido y espinoso tema de la autodeterminación. ${ }^{8}$

8 Vid. Suceda Irgo, A., The Evolution of the right of self-determination -A study of the United Nations Practice-, A. W., Sijthoff-Leiden, 1973, p. 397. Con toda razón señala Suceda: "After all, self-determination started off as an individual rights, and became a colective right because it was 
Independientemente de lo anterior, la práctica diplomática demuestra que un determinado "pueblo" que esté dotado de una organización suficientemente estructurada para ser capaz de llevar a cabo una acción internacional autónoma, y que goce además de un reconocimiento amplio en el seno de la comunidad internacional, puede y debe ser considerado como un actor internacional, basándose para ello y fundamentalmente en el principio de efectividad.

Si uno examina la práctica de Naciones Unidas, uno podría pensar que la Organización ha adoptado, grosso modo, la concepción según la cual la autodeterminación debe considerarse ya sea como un principio anticolonialista y antirracista, o como un principio de libertad en contra de la opresión de un Estado extranjero.

No obstante lo anterior, esta misma práctica parecería indicar también que el principio de la "autodeterminación de los pueblos" no engloba ni cubre los derechos de minorías y nacionalidades que habitan dentro de un mismo Estado soberano.

En este último sentido se dice que el principio de la "integridad territorial" de los Estados va a desempeñar un papel fundamental, ya que él mismo va a constituir una especie de barrera que el principio de autodeterminación no está autorizado a ignorar, salvo en los casos de excepción de dominación colonial o de un gobierno racista.

El proceso de descolonización produjo la formación de un gran número de nuevos Estados, pero cuya mayor parte se encontró inmersa en la condición de subdesarrollo absolutamente dramático.

La acción internacional de estos Estados, en particular en el seno de la Asamblea General de Naciones Unidas, daría nacimiento a una nueva rama del derecho, el llamado "derecho internacional del desarrollo", con vistas a conquistar una independencia económica y cultural, paralelamente a la independencia política ya lograda, es decir, con el anhelo de construir un nuevo orden económico internacional. ${ }^{9}$

En los últimos años y a raíz del colapso del modelo comunista, el movimiento secesionista fue ganando terreno en lo que fue la Unión Soviética. En ocasiones, las repúblicas miembros de la Unión proclamaban su

thought that individual rights could be better ezercised within a demonstrably coherent human group". Ibidem, p. 356.

9 Véase Gómez-Robledo Verduzco, Alonso, La soberanía de los Estados sobre sus recursos naturales, México, UNAM, 1980. 
plena soberanía internacional. De esta forma lo decidieron, por ejemplo, los parlamentos de las siguientes repúblicas: Federación de Rusia, el 12 de junio de 1990; Ucrania, el 16 de julio; Azerbaidjan, el 27 de julio; Bielorrusia, el 27 de julio; Carelia, el 10 de agosto; Armenia, el 23 de agosto y Tadjikstan, el 24 de agosto.

En otras ocasiones el procedimiento consistió en que las repúblicas proclamaban el principio de la supremacía de su Constitución y sus leyes particulares, por encima de la Constitución federal y las leyes soviéticas. A este procedimiento recurrieron las repúblicas de Georgia, el 20 de junio de 1990; de Turkemenistan, el 23 de agosto, y de Kazakhstan, el 26 de octubre del mismo año.

Los últimos acontecimientos han sido muestra fiel de que en múltiples casos "el principio de no intervención" se ha visto enfrentado al "principio de autodeterminación".

Ésta era ni más ni menos la formulación ideológica del dilema en Yugoslavia. Si los terceros Estados rehusaban el reconocimiento de Eslovenia y Croacia, esto constituía al mismo tiempo un rechazo a la intervención en los asuntos internos de Yugoslavia, y por el contrario, otorgar su reconocimiento implicaba la reconfirmación del principio de la autodeterminación. De ahí que siempre se tuviera en cuenta el hecho de que la demanda de reconocimiento surgiera de las mismas repúblicas, y que fuera la expresión auténtica de la voluntad popular.

México ha proclamado, en forma casi constante y uniforme a lo largo de su historia, el derecho de los pueblos a su libre determinación, y es sin duda uno de los principios que han normado la conducción de su política exterior.

Además de ello, México ha afirmado y ratificado convenciones internacionales de una gran trascendencia, donde se consagra dicho principio, como es el Pacto Internacional de Derechos Económicos, Sociales y Culturales y el Pacto Internacional de Derechos Civiles y Políticos de 1966, ambos jurídicamente vinculantes para México desde 1981:

1. Todos los pueblos tienen el derecho de libre determinación. En virtud de este derecho establecen libremente su condición política y proveen asimismo a su desarrollo económico, social y cultural.

2. Para el logro de sus fines, todos los pueblos pueden disponer libremente de sus riquezas y recursos naturales sin perjuicio de las obligaciones que derivan de la cooperación económica internacional basada en el principio de beneficio recíproco así como del derecho internacional. En 
ningún caso podrá privarse a un pueblo de sus propios medios de subsistencia. ${ }^{10}$

\section{LA SOLUCIÓN PACÍFICA DE CONTROVERSIAS}

Si analizamos el principio fundamental de la "solución pacífica de las controversias", no cabe duda que rebasa el marco de los Estados miembros de las Naciones Unidas.

Este principio se encuentra inserto en la mayoría de los instrumentos internacionales concernientes al mantenimiento de la paz y la seguridad; reviste, por lo tanto, más allá de su proclamación convencional —en tratados y acuerdos-, el valor consuetudinario de un principio general de derecho internacional que obliga a todos los Estados; esto no equivale a que pueda también atribuírsele un valor de norma imperativa de jus cogens. ${ }^{11}$

Los Estados están obligados a solucionar por medios pacíficos sus controversias internacionales. Para escapar a esta obligación, los Estados pueden pretender que la situación conflictual a la cual se encuentran confrontados, y que puede haber desembocado en el uso de la fuerza, no constituye un "diferendo", o incluso admitir que existe una controversia, pero que ésta no constituye una controversia de carácter internacional.

Este principio es, indudablemente, históricamente anterior al principio de la prohibición del empleo de la fuerza. Bajo este preciso aspecto de búsqueda de soluciones a los disentimientos entre Estados se suscribió la Convención de La Haya de 1907, en vistas a prevenir, tanto y como fuere ello posible, el recurso a la fuerza en las relaciones internacionales.

La noción de "diferendo" implica un objeto suficientemente circunscrito, a diferencia de la "situación", que es más difusa, y casi siempre previa al nacimiento de una controversia.

Pero la noción de "diferendo" implica también la noción de que haya "partes", entre las cuales ha surgido una divergencia de puntos de vista; y como el diferendo es internacional, dichas partes no son otros sino los Estados.

De aquí que un diferendo internacional supone que las partes reconocen recíprocamente la calidad jurídica de entidades estatales. Al no existir

10 Artículo 1o., parte 1, de ambos pactos internacionales.

11 Véase Gómez-Robledo, Antonio, El ius cogens internacional, México, UNAM, IIJ, 1982 (estudio histórico-crítico). "Ius Cogens is a necessary component of any legal ordern": definición del jurista soviético Alexidze, citada por Gómez-Robledo, Antonio, op. cit., p. 227. 
ninguna obligación de reconocimiento, es frecuente que una de las partes se mantenga en su posición, tratando de encontrar un compromiso más favorable. ${ }^{12}$

Todos los procedimientos para solución de controversias son en derecho internacional "medios voluntarios", en el sentido de que no pueden ser puestos en marcha sin que exista, previa y forzosamente, el consentimiento de las partes involucradas. En este sentido, bien puede hablarse de una contradicción entre la obligación general de arreglo de controversias y el carácter eminentemente facultativo de cada uno de los medios y procedimientos que permitirían concretar la obligación general.

De ahí que para esta situación contradictoria diversas técnicas y procedimientos permitan a los Estados comprometerse con antelación para eventualmente someter un diferendo en el marco del instrumento ya negociado.

Éste es precisamente el objeto de las llamadas "cláusulas compromisorias" de los tratados de arbitraje; de los acuerdos de conciliación, o incluso de la famosa "cláusula facultativa de jurisdicción obligatoria", por la cual los Estados reconocen como obligatoria ipso facto, y sin convenio especial, la jurisdicción de la Corte Internacional de Justicia, respecto de cualquier otro Estado que haya aceptado la misma obligación (artículo 36 del Estatuto). ${ }^{13}$

Ahora bien, la distinción entre los "medios diplomáticos" y los "medios jurisdiccionales" es una distinción clásica y esencial en derecho internacional.

Los "medios diplomáticos", como los buenos oficios y la mediación, o aquellos tributarios de la "diplomacia parlamentaria", en el seno de las organizaciones internacionales, son medios que pueden ser utilizables y apropiados para cualquier tipo de diferendo, sea de la naturaleza que fuere, y sin que la decisión esté provista de fuerza obligatoria.

12 Véase Charpentier, Jean, Cot et Pellet, Charte des Nations Unies, pp. 103-112. El conflicto árabe-israelí es ilustrativo de esta situación. Al principio, los Estados árabes rehusaban a Israel la calidad jurídica de ser un Estado y el derecho a su existencia, para que tiempo después fuese el mismo Estado hebreo quien rehusara reconocer a la OLP como un interlocutor válido y representativo del Estado palestino. Ibidem, p. 108.

13 El artículo 33 de la Carta de la ONU dice: "Las partes en una controversia cuya continuación sea susceptible de poner en peligro el mantenimiento de la paz y la seguridad internacionales tratarán de buscar solución, ante todo, mediante la negociación, la investigación, la mediación, la conciliación, el arbitraje, el arreglo judicial, el recurso a organismos o acuerdos regionales u otros medios pacíficos de su elección”. Este artículo 33 de la Carta de la ONU encuentra su contraparte regional en el artículo 24, capítulo V de la Carta de la OEA, en términos cuasi idénticos. 
Por el contrario, los "medios jurisdiccionales" no pueden ser utilizados más que para los diferendos jurídicos; implican un arreglo o solución emanada de un órgano constituido para que, al término de un proceso, dicte una decisión vinculante sobre la base del derecho. ${ }^{14}$

\section{LA PROSCRIPCIÓN DE LA AMENAZA O EL USO DE LA FUERZA EN LAS RELACIONES INTERNACIONALES}

El principio de la prohibición de la amenaza o el uso de la fuerza es probablemente la traba central del mecanismo de seguridad de las Naciones Unidas: "Los Miembros de la Organización, en sus relaciones internacionales, se abstendrán de recurrir a la amenaza o al uso de la fuerza contra la integridad territorial o la independencia política de cualquier Estado, o en cualquier forma incompatible con los Propósitos de las Naciones Unidas" (artículo 2o., párrafo 4).

Sin embargo, este "principio de principios" comporta limitaciones y ambigüedades que se han dejado entrever a lo largo de la historia de las relaciones internacionales.

Las limitaciones surgen, antes que nada, del hecho que el recurso al uso de la fuerza no esté prohibido más que en el marco de las relaciones internacionales, y en razón únicamente de su finalidad, esto es, que sea llevado en contra de la integridad territorial y la independencia política de

14 Thierry, Hubert, "Le règlement pacifique des différends et l'ajustement des situations conflictuels", en Thierry, Combacau, Sur, Vallé, Droit International Public, 3èeme edition, París, Précis Domat, Éditions Montchrestiens, 1981, pp. 555-601. Hasta la fecha han sido tres los juristas de nacionalidad mexicana que han sido jueces ante la Corte de La Haya: Isidro Fabela (1946-1952), Roberto Córdova (1955-1964) y don Luis Padilla Nervo (1964-1973). Igualmente, hay que resaltar que México hasta el día de hoy no ha sido parte en contencioso alguno ante la Corte. Sin embargo, nuestro país tuvo participación, junto con otros países, en la Opinión Consultiva de 1996, solicitada por la Asamblea General de la ONU en el Caso de la Licéit, de la Menace ou de l'Emploi d'Armes Nucleaires, y en donde sostuvo la Corte por 11 votos a favor y 3 en contra que "Ni el derecho internacional consuetudinario, ni el derecho internacional convencional, no comportaban prohibición completa y universal de la amenaza o del uso de armas nucleares en tanto que tales", Avis Consultatif, CIJ, 8-07-96. Por el contrario, México, durante su historia, ha hecho uso del arbitraje internacional en varias ocasiones; por una parte, en las numerosas comisiones mixtas de reclamaciones del siglo XIX y del siglo XX, y, por la otra, en los tres famosos casos sometidos por México al arbitraje en 1902, a saber: el "Caso del Fondo Piadoso de las Californias", fallado por la Corte Permanente de Arbitraje en 1902; “el Caso de la Isla Clipperton, Pasión o Médanos" de 1931, sometido al rey de Italia, Víctor Manuel III; y "el Caso del Chamizal de 1911" fallado por un tribunal de arbitraje constituido por la Convención de Arbitraje de 1910. Para el análisis de estos tres célebres arbitrajes véase la obra exhaustiva de Gómez-Robledo, Antonio, México y el arbitraje internacional, México, Porrúa, 1965, p. 412. 
todo Estado, o de cualquier otra manera que sea incompatible con los propósitos de Naciones Unidas.

De toda evidencia, lo anterior quiere decir — así sea implícitamente-, que el recurso al uso de la fuerza puede ser un recurso legítimo dentro de ciertas circunstancias, o en vista de determinados fines u objetivos.

La principal excepción a la prohibición del recurso al uso de la fuerza se encuentra en "el derecho a la legítima defensa", ya sea individual o colectiva.

Si bien es indiscutible la necesidad de su inserción como una excepción fundamental, su alcance práctico es considerable, y su aplicación conlleva un problema de una dificultad extrema, como dice M. Virally, y que es ni más ni menos que el relativo al de la definición de la "agresión", la cual va a llegar a justificar o a legitimar el derecho mismo de defensa. ${ }^{15}$

Uno de los problemas con los que siempre se ha enfrentado el artículo 2o., párrafo 4, es el de determinar si la prohibición de la fuerza es únicamente la calificada de "militar", o bien, como siempre han pugnado los países latinoamericanos, que la prohibición del artículo 2o., párrafo 4, cubre todas las manifestaciones de fuerza, incluyendo las presiones políticas, económicas y otras. ${ }^{16}$

Es importante señalar que en la Convención de Viena de 1969 sobre el Derecho de los Tratados, ratificada por México en 1974, y en vigor desde 1980, se estipula en sus disposiciones 51 y 52, que la coacción sobre el representante de un Estado en obligarse por un tratado carecerá de todo efecto jurídico (nulidad absoluta), y por otro lado, que será igualmente nulo, ab initio, todo tratado cuya celebración se haya obtenido por la amenaza o el uso de la fuerza, en violación de los principios de la Carta de la ONU.

15 Véase Virally, Michel, "L’article 2: paragraphe 4", La Charte des Nations Unies, pp. 113-125.

16 Por otro lado, es verdad que contrariamente a las apariencias, como dice Virally, la famosa Resolución 3314 (XXIX) sobre la definición de la "agresión” adoptada por la Asamblea General de la ONU en 1974, no resuelve el problema mismo que se deseaba solucionar. Ibidem, pp. 115 y 116. Véase The Concept of Agression in International Law, Foreword by Charles O. Galvin, Dallas, Southern Methodist University Press, 1972, p. 114. Estos autores sostienen, con relación a la agresión de tipo económico, lo siguiente: "Perhaps the definition should include and combine both meanings, i.e., illegal economic measures employed by state against another state so as to force the sovereign will of the latter and to deprive it of economic ressources or disturb its economic life, thereby jeopardizing its security", ibidem, p. 92. 
La Conferencia de Viena de 1969 aprobó, como formando parte del acta final, una declaración por la cual se condena el recurso a la amenaza o al uso de la presión, en todas sus formas, ya sea militar, política o económica, por un Estado, “con el fin de coaccionar a otro Estado para que realice un acto relativo a la celebración de un tratado en violación de los principios de la igualdad soberana de los Estados y de la libertad del consentimiento". ${ }^{17}$

\section{LA IGUALDAD JURÍDICA DE LOS ESTADOS}

El principio de la "igualdad jurídica de los Estados" tiene como significación primera, que no obstante las diferencias de poder, de adelanto o de industrialización de los Estados, todo Estado como sujeto de derecho internacional es titular de los mismos derechos y de las mismas capacidades, a la par de cualquier Estado tercero.

Este postulado lo encontramos entre los principios fundamentales de las Naciones Unidas, como una de las ideas-clave para la realización de los propósitos de la organización: "La Organización está basada en el principio de la igualdad soberana de todos sus Miembros" (artículo 2o., párrafo 1).

Por su parte, la Carta de la Organización de Estados Americanos retoma este mismo principio, pero de modo más detallado: "Los Estados son jurídicamente iguales, disfrutan de iguales derechos e igualdad de capacidad para ejercerlos, y tienen iguales deberes. Los derechos de cada uno no dependen del poder de que disponga para asegurar su ejercicio, sino del simple hecho de su existencia como persona de derecho internacional" (artículo 9o.).

Posiblemente, habría sido más conveniente hablar de "igualdad soberana", como lo hace la Carta de la ONU, ya que en estricto rigor la independencia viene a ser un corolario y la manifestación concreta de la "soberanía".

El derecho de un Estado de rechazar toda injerencia es precisamente la consecuencia directa y la traducción concreta de su soberanía. ${ }^{18}$

17 Véase Conferencia de las Naciones Unidas sobre el Derecho de los Tratados, Documento Oficial, A/CONF.39/11/Add 2. Esta importante Declaración fue lo más que pudieron lograr los países en vías de desarrollo; obviamente, por ser parte del acta final de la Conferencia no goza de la fuerza jurídica vinculante.

18 Véase Lachrrière, Guy, "L'influence de l'inégalité de développement des Etats sur le droit international”, Recuiel des Cours de l'Académie de Droit International, vol. II, 1973, pp. 227-268. 
De este principio de la igualdad jurídica de los Estados se deriva, en el terreno concreto de la teoría de las inmunidades, un primer y esencial derecho, consistente en que ningún Estado puede ser emplazado ante una jurisdicción interna extranjera si no media necesariamente el otorgamiento expreso de su consentimiento.

Del anterior derecho se sigue como corolario que no se puede emprender contra Estado alguno una acción de oficio, cualquiera que ésta sea, en contra de sus bienes, derechos y haberes, sitios en territorio extranjero. En otras palabras, esta última, la inmunidad de ejecución, viene a complementar su inmunidad de jurisdicción, la cual, podemos decir, está en relación de causa-efecto.

En la muy importante Resolución 2625 (XXV) de la Asamblea General de la ONU (1970), llamada "Declaración sobre los principios de derecho internacional referentes a las relaciones de amistad y a la cooperación entre los Estados de conformidad con la Carta de las Naciones Unidas", se habla igualmente de la consagración del principio de la "igualdad soberana" de los Estados:

Todos los Estados gozan de igualdad soberana. Tienen iguales derechos e iguales deberes y son por igual miembros de la comunidad internacional, pesos a las diferencias de orden económico, social, político o de otra índole.

En particular, la igualdad soberana comprende los elementos siguientes:

A) Los Estados son iguales jurídicamente;

B) Cada Estado goza de los derechos inherentes a la plena soberanía;

C) Cada Estado tiene el deber de respetar la personalidad de los demás Estados;

D) La integridad territorial y la independencia política del Estado son inviolables;

E) Cada Estado tiene el derecho a elegir y a llevar adelante libremente su sistema político, social, económico y cultural;

F) Cada Estado tiene el deber de cumplir plenamente y de buena fe sus obligaciones internacionales y de vivir en paz con los demás Estados. ${ }^{19}$

En general, la doctrina más representativa está de acuerdo en aceptar que esta Declaración ha sido una de las más importantes declaraciones

Hay que tener claro que, en el terreno de los hechos, es precisamente porque los Estados no son iguales, que se requiere necesariamente la proclamación de un principio de igualdad.

19 Véase Résolution 2625 (XXV), A.G. des Nations Unies, le 24 octobre 1970, Droit et relations internationales, textes choices par Hubert Thierry, París, Montchrestine, 1984, pp. 545-550. 
adoptadas por la comunidad internacional, y que ha tenido un impacto y una influencia mucho mayor de lo que se creía, en lo que se refiere al desarrollo del derecho internacional.

La Declaración de 1970 no pretende enmendar la Carta de la ONU, sino esclarecer y clarificar mayormente los principios jurídicos básicos, contenidos en el artículo 2o. de la Carta, y en algunos otros aspectos, situándose entre las exigencias de lege lata, y las presiones para el reconocimiento de un emergente cuerpo normativo de lege ferenda.

Una declaración de esta naturaleza aprobada por unanimidad parece difícil, como decía Jiménez de Aréchaga, que le pueda ser negado el peso jurídico y la autoridad de una declaración en su doble faceta: primero como resolución, reconociendo aquello que los miembros mismos de Naciones Unidas piensan que constituye las normas existentes de derecho consuetudinario, y en su segunda faceta, como un instrumento interpretativo de la Carta por acuerdos subsecuentes y práctica posterior de todos sus miembros. ${ }^{20}$

\section{LA COOPERACIÓN INTERNACIONAL PARA EL DESARROLLO}

A pesar de la primacía que se otorga en la Carta de la ONU a los problemas específicos de seguridad internacional, la cooperación económica y social ocupa un lugar importante, y nada desdeñable.

La cooperación internacional debe, antes que nada, permitir crear las condiciones de estabilidad y bienestar necesarios para las relaciones pacíficas y amistosas entre las naciones, basadas en el respeto al principio de la igualdad de derechos y al de la libre determinación de los pueblos, como se consagra en el artículo 55 de la Carta.

Si bien es evidente que el objetivo final es de índole política, se definen igualmente diversos objetivos de naturaleza económica, entre los que destacan el promover "niveles de vida más elevados, trabajo permanente para todos, y condiciones de progreso y desarrollo económico y social" (artículo 55, inciso a).

Estos objetivos, que serían gradual pero sistemáticamente desarrollados, primeramente a través de las resoluciones y decisiones de la Asamblea General de Naciones Unidas, se apoyaban en la convicción de que el

20 Véase Jiménez de Aréchaga, E., "International Law in the Past Third Century", Recueil des Cours de l'Académie de la Haye, 1978, vol. I, núm. 159. 
fenómeno del subdesarrollo presentaba un carácter mundial, que aparejaba consecuencias perturbadoras, no solamente para los países directamente interesados, sino para el mundo entero, que estaría amenazado de una grave inestabilidad, por el hecho del fuerte desequilibrio económico que se presentaba.

Con el tiempo, la exactitud de este tipo de apreciaciones comenzó a hacerse más evidente.

La división entre países industrializados y países no industrializados, dejados estos últimos al margen de las ventajas resultantes de los progresos de la ciencia y la tecnología, es muchísimo más grave y de efectos más duraderos, que las famosas divisiones de tipo ideológico.

Las oposiciones ideológicas, como dice Michel Virally, pueden atenuarse, ya que no constituyen en sí mismas un obstáculo infranqueable para que se lleve a cabo una fructuosa colaboración, como puede ser advertido por todos y cada uno de nosotros.

Por el contrario, el abismo que llega a separar a los países en vías de desarrollo introduce, dice M. Virally, un elemento de desequilibrio fundamental en el seno mismo de la economía mundial, cuyas consecuencias políticas a largo plazo son impredecibles y de alto riesgo, y que no podrían suprimirse o atenuarse, sino por medio de una mejora sustancial en el desarrollo de las economías que presentan un gran rezago, frente a las altamente industrializadas.

La ideología de la descolonización apreciada conjuntamente con la ideología del desarrollo constituyeron en su tiempo y sin lugar a dudas, el elemento motor más poderoso en el seno del sistema de Naciones Unidas para los países con economías precarias y altamente inestables. ${ }^{21}$

\section{LA LUCHA POR LA PAZ Y LA SEGURIDAD INTERNACIONALES}

A la par que las proposiciones de Dumbarton-Oaks, la Carta de Naciones Unidas postula el mantenimiento de la paz y la seguridad, como el primer y principal "propósito" de la Organización.

La paz de la cual se hace mención es la paz en las relaciones internacionales, es decir, el mantenimiento de la "paz internacional".

21 Véase Virally, Michel, L'Organisation Mondiale, sous la direction de Rene-Jean Dupuy, París, Colin, 1972 (Collection U). En particular, véase el título III de la 2a. parte, en donde se analiza cuidadosamente a la ONU como instrumento de desarrollo, pp. 353-407. Véase igualmente Sohn B. Louis, Cases on United Nations Law, 2a. ed. rev., Brooklin, The Foundation Press, 1967, p. 1072. 
Esto parece significar que la intención expresa no es — salvo incidentalmente y como resultante de problemas de tipo internacional-, la de preservar la paz al interior de los Estados, o la de intervenir en conflictos bélicos de orden interno.

Tomando en cuenta la observación anterior, no cabe duda que este principio del mantenimiento de la paz y la seguridad internacionales es a la vez propósito y objetivo primordial de la organización, simple y sencillamente porque en ausencia de éste, difícilmente se puede alcanzar la finalidad de otros principios, o la creación de condiciones básicas para la consecución de los demás objetivos y propósitos fijados por la Carta.

Ahora bien, es claro que la Carta de Naciones Unidas no ofrece una fórmula mágica, capaz de hacer frente a todo tipo de situación en que se vea amenazada la paz y la seguridad internacionales. La Carta ofrece únicamente un marco específico para su aplicación; ésta adjudica a todos y cada uno de los Estados miembros una serie de derechos y obligaciones para actuar colectivamente y en concierto, cada vez que cualquiera de ellos sea objeto de una amenaza contra la paz, de una violación de la paz o de un acto de agresión.

El sistema mismo de seguridad va a fundamentarse en un mecanismo de cooperación con el fin de poder actuar en forma conjunta en defensa del Estado víctima de una agresión. A la vez, su buen o mal funcionamiento va a depender de la cooperación misma entre los miembros permanentes del Consejo de Seguridad, y en general de la eficacia global que vaya mostrando este último órgano. ${ }^{22}$

Otro aspecto que es importante destacar en este principio referente al mantenimiento de la paz y la seguridad internacionales es el hecho de que para lograr su plena realización, los Estados deben lograr por medios pacíficos "el ajuste o arreglo de controversias o situaciones internacionales susceptibles de conducir a quebrantamientos de la paz" (artículo 1o., párrafo 1).

Independientemente de advertir el grado de vinculación e interdependencia de los principios de política exterior, es también importante darnos cuenta que si bien sería utópico pensar que todo diferendo puede ser solucionado por los medios tradicionales, sin embargo, como decía el antiguo presidente de la Corte de La Haya, Manfred Lachs, siempre queda la po-

22 Véase Goodrich M., Leland et Eduard Hambro, Commentaire de la Charte des Nations Unies, Neuchatel, Suisse, ed. établie par André-Marie Guymat, Éditions de la Baconnière, 1948, pp. 119-122, y Manfred, Lachs, “Article 1, paragraphe 1”, La Charte des Nations Unies, cit., pp. 31-38. 
sibilidad de "ajustar" las situaciones internacionales en el interés de las partes interesadas. El arreglo de las controversias es una operación más ambiciosa, cuyo objetivo es poner punto final a un litigio. Sin embargo, tanto el "ajuste" como el "arreglo" apuntan ambos a prevenir un quebrantamiento de la paz. ${ }^{23}$

Por último, hay que constatar que si bien el sistema de seguridad colectiva definido por la Carta de la ONU se caracterizó desde un principio por su realismo, también es cierto que este mismo se caracterizó por una gran ambición. La implementación del aparato militar que constituía la pieza clave del sistema a través de los "convenios especiales del artículo 43”, comprometiéndose a poner a disposición del Consejo de Seguridad las fuerzas armadas necesarias para el propósito de mantener la paz y la seguridad internacionales, nunca llegaron a celebrarse, y por lo tanto el edificio estaba condenado a desplomarse. ${ }^{24}$

\section{CONCLUSIÓN}

Al término de este sucinto examen de los principios rectores de nuestra política exterior, elevados a rango constitucional, y sin dejar de tomar en cuenta las consideraciones emitidas al principio del trabajo, no cabe duda que su elevación al plano constitucional permite una mayor difusión y propagación de éstos, lo cual tiene que redituar en un mejor conocimiento, profundización y estricto apego a los mismos.

De igual manera, debemos tener plena convicción de que para un país como México, el derecho internacional no puede ser un mero modo de expresión secundario de una política exterior.

Nosotros no podemos darnos el lujo de querer poseer una política exterior moldeable a las circunstancias del momento; un mero ropaje de luces cortado de acuerdo a las necesidades que se presumen prioritarias dentro de tal o cual coyuntura política.

23 Véase Manfred, Lachs, op. cit., nota 22, pp. 34 y 35.

24 Véase Virally, Michel, L'Organisation Mondiale, op. cit., nota 21, Chapitre 21, pp. 468-482. En tanto que el Comité de Estado Mayor no funcione, según los términos de la Carta de la ONU (artículo 45), y en tanto no se ponga a disposición de la organización, fuerzas armadas permanentes y los medios logísticos necesarios, las Naciones Unidas dependerán siempre de las potencias susceptibles de servirles como su brazo secular. Véase Smouts, Marie-Claude, "Le Conseil de Securité", Aspects du Système des Nations Unies dans le cadre de l'idée d'un nouvel ordre mondial, París, Pedone, 1992, pp. 61-69 (Colloque d'Aix-en-Provence, Yves Daudet). 
El derecho internacional debe ser nuestro instrumento por antonomasia para mantener una posición política de independencia, y esto es "realismo puro", y no posturas "legalistas". 25

El buen sentido siempre ha demostrado que un país más débil debe buscar siempre la instauración de un sistema que no permita a los más poderosos arrogarse una total libertad de interpretación del derecho, directamente proporcional a la capacidad de su poderío militar y económico.

25 Ver Castañeda, Jorge, "México y el nuevo orden mundial: actualidad y perspectivas", México y los cambios de nuestro tiempo, México, UNAM-CONACULTA-FCE, 1992, vol. III, pp. 263264. Este mismo jurista al analizar las relaciones con los Estados Unidos, sostiene sin ambages que: “... En las relaciones entre los dos países, no hay ninguna credibilidad a una buena voluntad por parte de Estados Unidos intempestivamente descubierta o redescubierta... Las grandes potencias actúan siempre como grandes potencias", ibidem, p. 264. 